\title{
FASILITAS KEBUGARAN DAN REKREASI DI SETIABUDI
}

\author{
Ariwibowo Setiawan $^{1}$, Dewi Ratnaningrum ${ }^{2}$ \\ 1) Program Studi S1 Arsitektur, Fakultas Teknik, Universitas Tarumanagara, ariwibbb97@gmail.com \\ 2) Program Studi S1 Arsitektur, Fakultas Teknik, Universitas Tarumanagara, dewitrionotasman@gmail.com
}

Masuk: 09-01-2020, revisi: 27-01-2020, diterima untuk diterbitkan: 09-05-2020 (doi: 10.24912/stupa.v2i1.6752)

\begin{abstract}
Abstrak
Manusia sebagai makhluk sosial selalu membutuhkan interaksi sosial dengan sesamanya dalam daur hidupnya. Ruang publik telah menjadi latar bagi perkembangan kehidupan publik, baik dalam kegiatan ekonomi, sosial, hiburan, hingga politik. Berlangsungnya kehidupan publik dengan interaksi sosial menjadi salah satu faktor yang sangat bergantung pada keberadaan dan perkembangan ruang publik. Minimnya ruang publik di kawasan Setiabudi mengakibatkan masyarakat menciptakan ruang publik di jalan lingkungan permukimannya sebagai tempat untuk bersosialisasi dan beraktivitas. Kegiatan-kegiatan yang menggunakan jalan sebagai media beraktivitas dan bersosialiasi sehari-hari cenderung mengganggu serta berbahaya bagi warga. Selain itu, sebagian penghuni di kawasan Setiabudi merupakan pendatang dari luar kawasan tersebut yang ingin bekerja dan bermukim sehingga menyebabkan kesenggangan sosial antara pendatang dan penduduk Setiabudi. Tujuan proyek adalah mengurangi degradasi sosial dan lingkungan antara pendatang dan penghuni Setiabudi. Dari isu-isu tersebut, dapat disimpulkan bahwa kawasan Setiabudi membutuhkan fasilitas-fasilitas untuk melengkapi kebutuhan sosial harian penduduk dan kebutuhan sekunder pendatang yang bekerja sekaligus bermukim di kawasan Setiabudi. Metode penelitian yang digunakan adalah melalui studi literatur, studi preseden. Selain itu, dilakukan juga teknik pengamatan langsung yaitu wawancara dan dan observasi ke beberapa permukiman, fasilitas sosial dan umum. Oleh karena itu, mereka membutuhkan fasilitas seperti flexible space (ruang serbaguna), gym, kid's play area, bar dan ruang rekreasi dengan fasilitas pendukung seperti food court dan co-working space. Fasilitas Kebugaran dan Rekreasi ini memiliki konsep oasis-maker yang mengutamakan inklusivitas antar sesama manusia serta bersifat netral dan memiliki kesan playful.
\end{abstract}

\section{Kata kunci: inklusif; komunitas; menyenangkan; netral}

\begin{abstract}
Humans are highly social beings with great desire for social belonging and interpersonal exchange in their life. Public space has become a cornerstone of public growth consisting economic, social, entertainment, and political enterprise. Therefore, the continuation of public interaction become very dependent on both public space existence and growth. The inadequacy of public space in Setiabudi has provoked the community to create public spaces in their residential roads to socialize and do various activities. Nonetheless, using roads as public infrastructure for daily activities and socializing may resulted in inconvenience and hazardous situation. In addition, most inhabitants in Setiabudi are migrants with the incentive to work and settle which resulted in social discrepancy. If this problem is not anticipated immediately, social and environmental degradation may arise. From these issues, we can conclude that Setiabudi need some facilities to fulfill the social needs of inhabitants and migrants secondary needs to work and settle. The research method conducted is through literature studies, precedent studies. In addition, direct observation techniques were also carried out namely interviews and observations to several settlements, social and public facilities. Therefore, facilities such as flexible space, gym, kid's play area, bar, and recreational space for food court and co-working space are essential. Along with the oasis-maker concept, Setiabudi Wellness and Recreation Facility undertake inclusivity of human, neutrality, and playfulness.
\end{abstract}

Keywords: community; inclusivity; neutral; playful 


\section{PENDAHULUAN}

Manusia sebagai makhluk sosial selalu membutuhkan interaksi sosial dengan sesamanya dalam daur hidupnya. Ruang publik telah menjadi latar bagi perkembangan kehidupan publik, baik dalam kegiatan ekonomi, sosial, hiburan, hingga politik. Berlangsungnya kehidupan publik dengan interaksi sosial menjadi salah satu yang sangat bergantung pada keberadaan dan perkembangan ruang publik.

Minimnya ruang publik sebagai akibat pengembangan yang hanya berorientasi pada kepentingan diri sendiri, mengakibatkan masyarakat mengatasinya secara mandiri. Mereka mengadakan sendiri ruang publik di lingkungan pemukimannya dengan kemungkinan akses yang lebih besar. Sebuah lapangan terbuka di tengah permukiman sering menjadi pusat sosialisasi para warga.

Di permukiman Setiabudi sendiri, jalan-jalan pada perumahan hingga perkampungan yang difungsikan oleh warga setempat sebagai ruang untuk bersosialisasi dengan tetangga atau tempat melakukan aktivitas seperti mencuci kendaraan, bermain, berolah raga (senam, bulu tangkis, sepak bola, jalan-jalan) atau dalam melakukan kegiatan besar warga seperti perayaan tujuh belasan, dan masih banyak lagi. Sementara interaksi median jalan sudah tentu ada dan sudah pasti mudah dan murah karena warga tidak perlu mengeluarkan banyak tenaga atau materi untuk menjangkaunya, tinggal berjalan keluar rumah saja. Keamanan dan kenyamanan relatif bisa dicapai karena dekat dengan rumah. Pengganggu yang utama adalah ketika ada kendaraan lewat sehingga beberapa aktivitas harus dihentikan.

Fenomena yang nampaknya terjadi di permukiman Kelurahan Setiabudi menandakan bahwa kebutuhan masyarakat akan ruang publik sangat tinggi dan perlu segera diantisipasi agar tidak terjadi degradasi lingkungan dan sosial. Sejak masuknya arus globalisasi dan didukung berkembangnya teknologi yang canggih membuat masyarakat indonesia mulai bersikap individualis, padahal dulunya Indonesia pada sejarah nenek moyang merupakan negara yang menerapkan dan menjunjung tinggi semangat gotong royong, serta mempunyai sikap sosial yang tinggi.

Proyek Fasilitas Kebugaran dan Rekreasi ini dimaksudkan sebagai sebuah wadah yang dapat mengambil bagian dari memenuhi kebutuhan third place akibat degradasi sosial di Jakarta. Selain itu proyek ini dapat menjadi sebuah wadah di mana masyarakat dapat bertemu, berbicara dan bermusyawarah hal terkait dengan masyarakat kawasan itu sendiri. Perancangan proyek mengacu pada tujuan perancangan bangunan sebagai berikut:

a. Melakukan kajian dan perancangan mengenai third place apa yang dapat mengakomodasi kebutuhan sosial masyarakat yang tinggal di daerah bisnis, komersial yang tinggi.

b. Melakukan kajian dan perancangan mengenai kegiatan penunjang apa yang cocok dan dapat menunjang kegiatan sosial di dalam third place.

Beberapa permasalahan yang dihadapi meliputi bagaimana cara memperkenalkan third place kepada masyarakat kota agar dapat mewadahi dan memfasilitasi kebutuhan penduduk asli dan lingkungan di kawasan Setiabudi? Third place seperti apa yang cocok untuk karakteristik penduduk asli Setiabudi? Program apa saja yang akan mewadahi kebutuhan penduduk asli dan lingkungan Setiabudi? Bagaimana pengaruh proyek terhadap karakteristik lingkungan? Bagaimana strategi perancangan terhadap konsep sustainable dan green building? Bagaimana pertimbangan lokasi tapak yang sesuai dengan proyek?

Batasan kajian penulisan ini adalah untuk mengetahui pengaruh dan hubungan antara sikap individualis masyarakat Indonesia akibat degradasi sosial dengan kebutuhan third place sebagai ruang sosial, maka diharapkan dengan studi dan kajian ini dapat menjawab kebutuhan sosial bagi masyarakat khususnya di kawasan Setiabudi yang memiliki tingkat bisnis dan komersial yang tinggi. Kebutuhan sosial masyarakat di dalam third place pada hal ini seperti: kebutuhan ruang, program ruang, program bangunan, interior, serta harapan masyarakat terhadap kebutuhan third place saat ini. Subjek yang menjadi sasaran penulisan dan penelitian 
ini meliputi seluruh masyarakat / penduduk kelurahan Setiabudi dan Siswa/i Sekolah Menengah Atas Negeri 3 Setiabudi. Dari beberapa target yang dicanangkan oleh PBB mengenai Sustainable Development Goal terdapat 3 target yang sekiranya sesuai dengan visi misi dari proyek hunian bagi generasi millenial, diantaranya:

\section{- Sustainable Cities And Communities}

Menyediakan third place sebagai wadah untuk memenuhi kebutuhan sekunder kawasan yang inklusif, terbuka, multi program dan mendukung terciptanya komunitas sosial maupun ekonomi yang baik, serta memberikan ruang terbuka publik bagi masyarakat baik dari dalam dan sekitar kawasan. Masyarakat perlahan-lahan akan yakin untuk menggunakan transportasi umum dengan adanya third place ini.

\section{- Good Health And Well - Being}

Menyediakan lingkungan hidup yang sehat seperti merencanakan dan merancang lapangan olahraga yang inklusif dan bisa digunakan oleh seluruh masyarakat Setiabudi serta menyediakan komunitas Setiabudi yang aktif dan positif untuk mencapai kehidupan yang sehat dan bermanfaat.

\section{KAJIAN LITERATUR}

Menurut (Rami Gabriel, 2015), seorang profesor psikologi di Columbia College Chicago, menyarankan bahwa:

"masyarakat individualis seperti Amerika Serikat, di mana modal sosial lemah dan ada sektor swasta yang berkembang dan sektor publik yang kelaparan, harus mencoba untuk mempertahankan dan memelihara beragam rentang hubungan non-komersial antara orang-orang dan ruang untuk hubungan ini terjadi. Kami berpendapat bahwa ruang seperti itu adalah yang dapat dan melakukan saling berbagi."

Menurut (Larice dan Macdonald, 2007).

"Istilah place erat kaitannya dengan teori space. Jika space berarti tiga dimensi yang membentuk place, sedangkan karakter diartikan sebagai suasana dari sebuah place. Edward Relp, Prospect of Place, berpendapat bahwa ada hubungan antara lanskap, pengalaman keseharian dengan faktor sosial dan ekonomi dalam pembentukan sebuah ruang. Istilah place dikaitkan dengan hubungan antara lanskap, pengalaman keseharian dengan faktor sosial sebagai tempat-tempat yang unik, lanskap, ruangruang komunal dibandingkan dengan pengalaman dan lingkungan tertentu."

Seperti dijelaskan oleh Ray Oldenburg (1999), third place berbagi fitur umum.

a. Mereka netral, artinya semua orang bisa datang dan pergi tanpa harus membayar.

b. Perbedaan status atau jabatan yang sangat penting di tempat lain tidak relevan dan tidak ada yang menjadi tuan rumah di tempat ketiga.

c. Percakapan adalah kegiatan utama di tempat ketiga, dan salah satu dari beberapa cara untuk menyinggung orang lain yang hadir adalah menjadi membosankan.

d. Tempat ketiga dapat diakses, artinya mereka memiliki jam yang panjang dan mudah dijangkau.

e. Tempat ketiga memiliki pengunjung tetap. Memang, pelanggan tetap menentukan tempat ketiga, tetapi orang baru diterima, tidak secara otomatis tetapi sering dengan mudah.

f. Tempat ketiga secara fisik sederhana dan bersahaja.

g. Suasana dominan dari tempat ketiga adalah menyenangkan. 


\section{METODE}

Metode perancangan yang digunakan proyek ini adalah metode trans-programming, yaitu metode yang menggabungkan dua program yang sifat dan konfigurasi spasialnya berbeda tanpa melihat kecocokannya (Tschumi, 2005). Di sisi lain, untuk kawasan yang aspek sosialnya lemah, harus mempertahankan dan memelihara beragam rentang hubungan non-komersial antara orang-orang dan ruang untuk hubungan sosial ini terjadi (Gabriel, 2015).

Untuk penentuan program olahraga dan hiburan untuk masyarakat kelurahan Setiabudi, akan dilakukan pengamatan lebih lanjut melalui literatur, studi dari internet dan studi ergonomi terhadap kebutuhan ruang di dalam third place. Selain itu dilakukan juga teknik pengamatan langsung (wawancara dan observasi) terhadap beberapa permukiman, fasilitas sosial dan umum yang ada di kelurahan Setiabudi.

Proyek ini menggabungkan kedua program utama yaitu sarana olahraga dan hiburan yang memiliki sifat dan konfigurasi spasial yang berbeda dan merupakan program utama yang digabungkan dengan pertimbangan kebutuhan sosial masyarakat khususnya masyarakat kawasan Setiabudi yang menjadi salah satu aspek yang berpengaruh dalam perancangan proyek. Untuk penentuan program utama third place yaitu olahraga dan hiburan di sekitar kelurahan Setiabudi, akan dilakukan pengamatan lebih lanjut melalui literatur, studi dari internet dan studi ergonomi terhadap kebutuhan ruang sosial masyarakat. Selain itu dilakukan juga teknik pengamatan langsung di sekitar kelurahan Setiabudi. Untuk menentukan program ruang penunjang third place maka dilakukan studi dari internet dan literatur yang disesuaikan dengan kebutuhan sosial masyarakat Setiabudi, juga melalui teknik pengamatan langsung di sekitar kelurahan Setiabudi.

\section{DISKUSI DAN HASIL}

\section{Pemilihan Tapak}

Tapak terpilih berada di tengah-tengah kawasan permukiman Setiabudi. Setelah melakukan survei ke permukiman tersebut, jumlah ruang publik masih sangat minim. Selain itu kawasan Setiabudi juga memiliki jumlah dan titik aktivitas kantor yang besar.

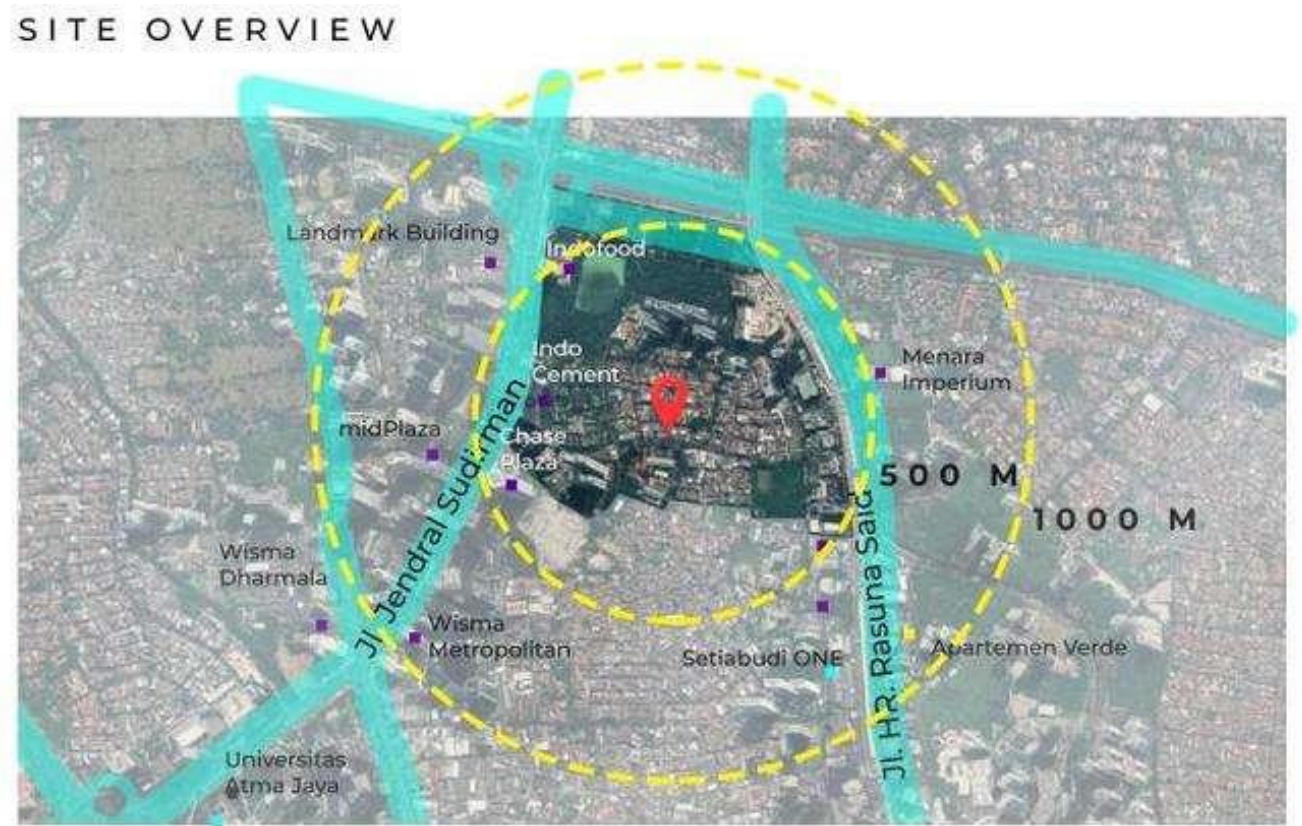

Gambar 1. Aktivitas Sekitar

Sumber: Penulis, 2019

Tapak Terpilih berada di antara zona first place yaitu permukiman Setiabudi dengan zona second place yaitu SMAN 3 dan perkantoran di sekitar. 


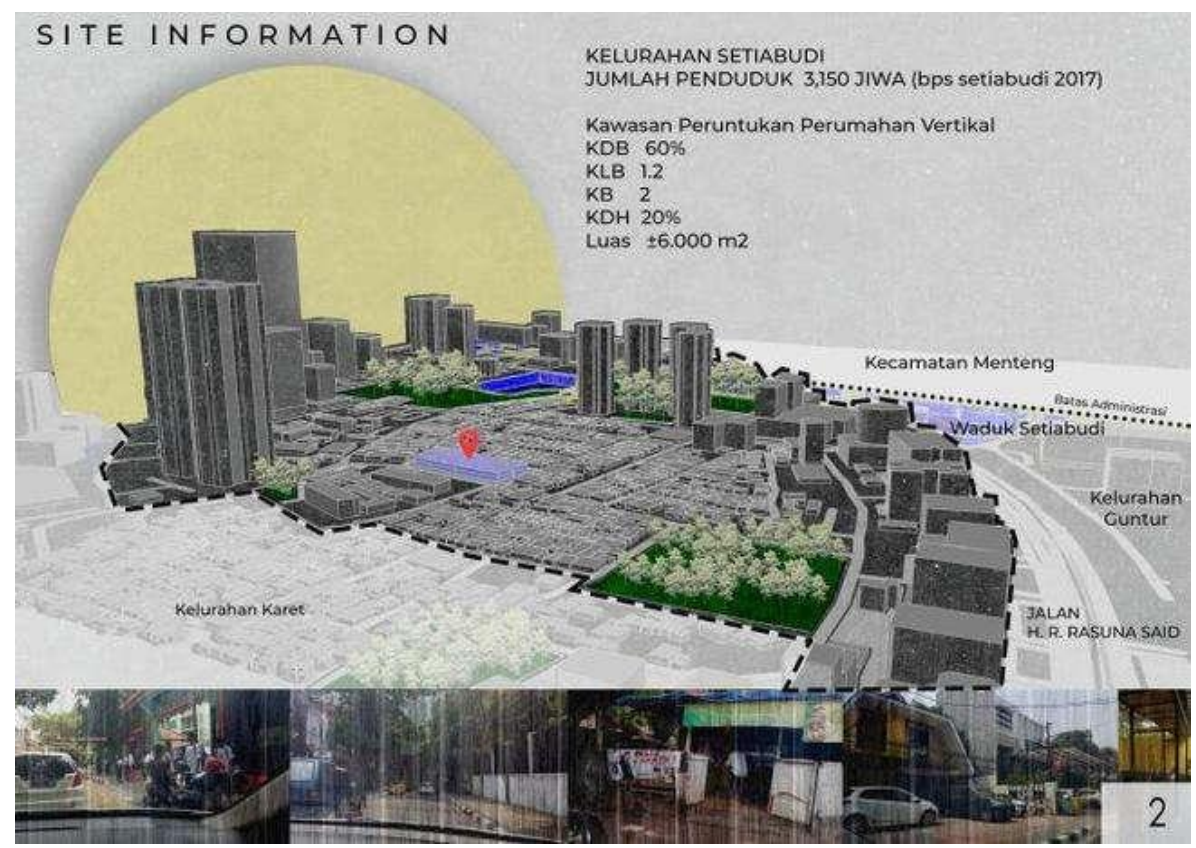

Gambar 2. Tapak Terpilih

Sumber: Penulis, 2019

\section{Program}

Program didasarkan kepada visi utama proyek yaitu sesuai dengan karakteristik dan budaya masyarakat Setiabudi yang cenderung kapitalis, diharapkan agar kebutuhan dan harapan terhadap third place bagi masyarakat Setiabudi dapat tercapai. Melalui third place yang sesuai kebutuhan sekunder, dan dapat menciptakan komunitas hidup yang aktif dan baik, dengan berbagai macam tempat komunal, produktifitas masyarakat yang membaik, kebutuhan sosial masyarakat yang tercukupi, sarana dan prasarana yang menunjang kehidupan bermasyarakat dan lain-lain.

\section{ARCHITECTURAL PROGRAM}
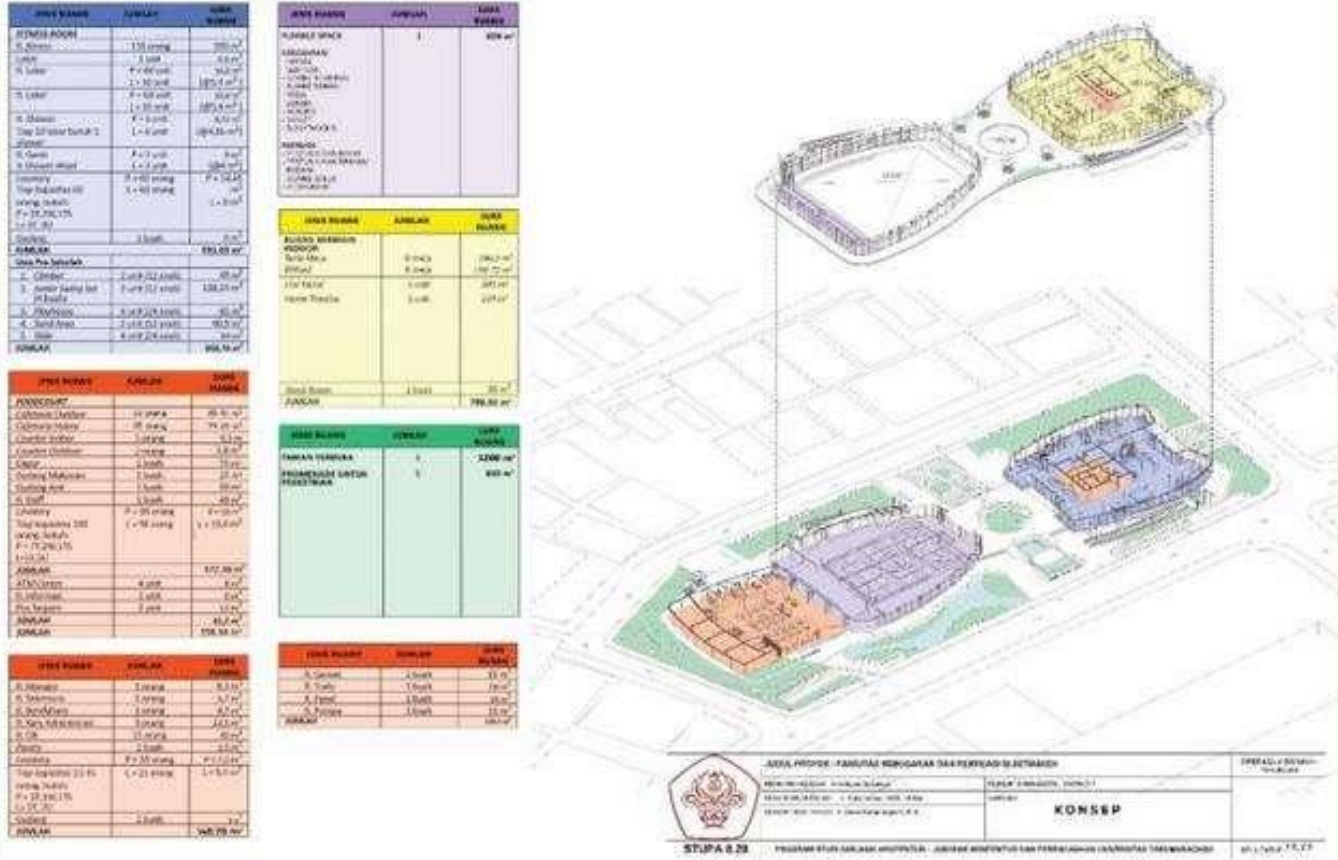

Gambar 3. Program Rancangan

Sumber: Penulis, 2019 


\section{Konsep}

Fasilitas Kebugaran dan Rekreasi ini memiliki konsep oasis-maker yang mengutamakan inklusivitas antar sesama manusia serta bersifat netral dan memiliki kesan playful. Oleh karena itu, proyek sebagai pusat berkumpul komunitas-komunitas (third place) harus bisa memberikan kesan oase, mudah diingat. Maka dari itu desain bangunan akan mendobrak konteks kawasan tersebut menjadi ruang terbuka publik yang akan menjadi area komunal bagi masyarakat sekitar.

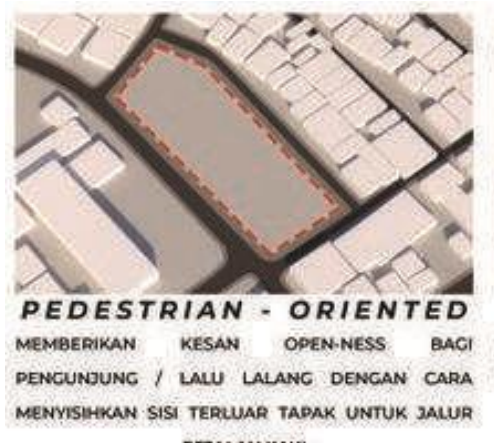

\section{PEALAN KaKI}

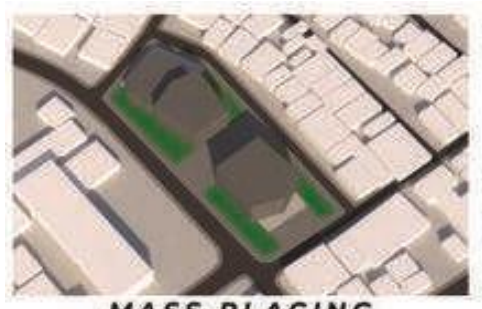

\section{MASS PLACINC}

MASSA BANCUNAN DESESUAKKAN PERATURAN KOTA ZONING DAN MENYAMBUNGKAN OENGAN PROCRAM BANCUNAN YATUU WELLNESS \& AECREATION

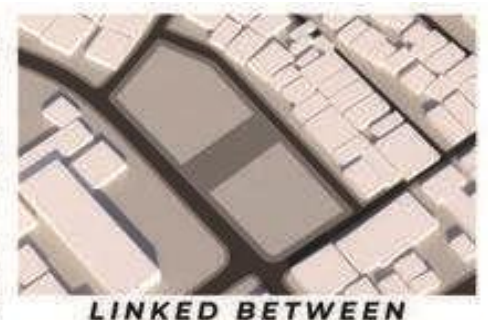

MEMBERTKKAN KEMUDAHAN BACI DEJALAN KAKR DENGAN CARA MENYAMBUNGKAN KEDUA JaLAN MELALUI TADAK

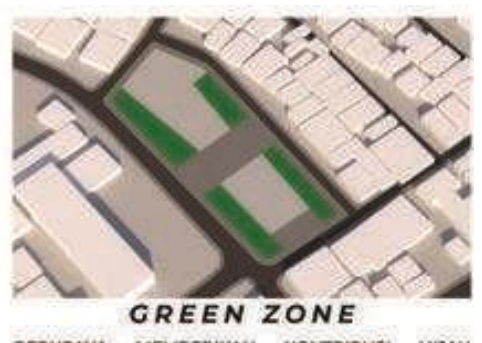

Berupaya MEMBerikan Kontbibusi hoAU KEPADA KAWASAN SETLABUDI DENGAN CARA MENYISIHKCAN MINIMAL, $20 \%$ TAPAK UNTUK AREA HDAU.

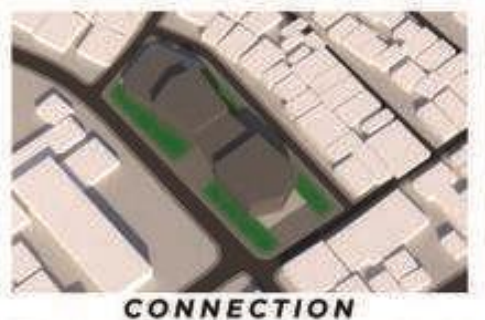
CONNECTION

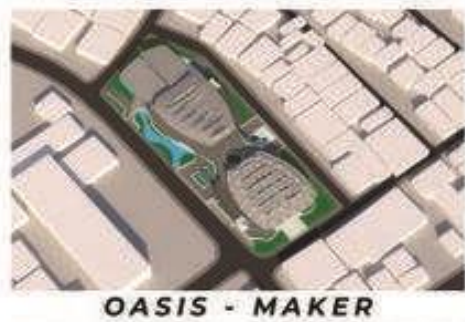

THIRD PLACE SEBACAL PUSAT BERKUMPUL KOMUNITAS HARUS BISA MEMBERIKAN KESAN OASE DENGCAN CARA MENDESAIN SENTUK EANCUNAN VANG KONTRAS DERGANBANCUNANSEKTAR

Gambar 4. Proses Gubahan Massa

Sumber: Penulis, 2019

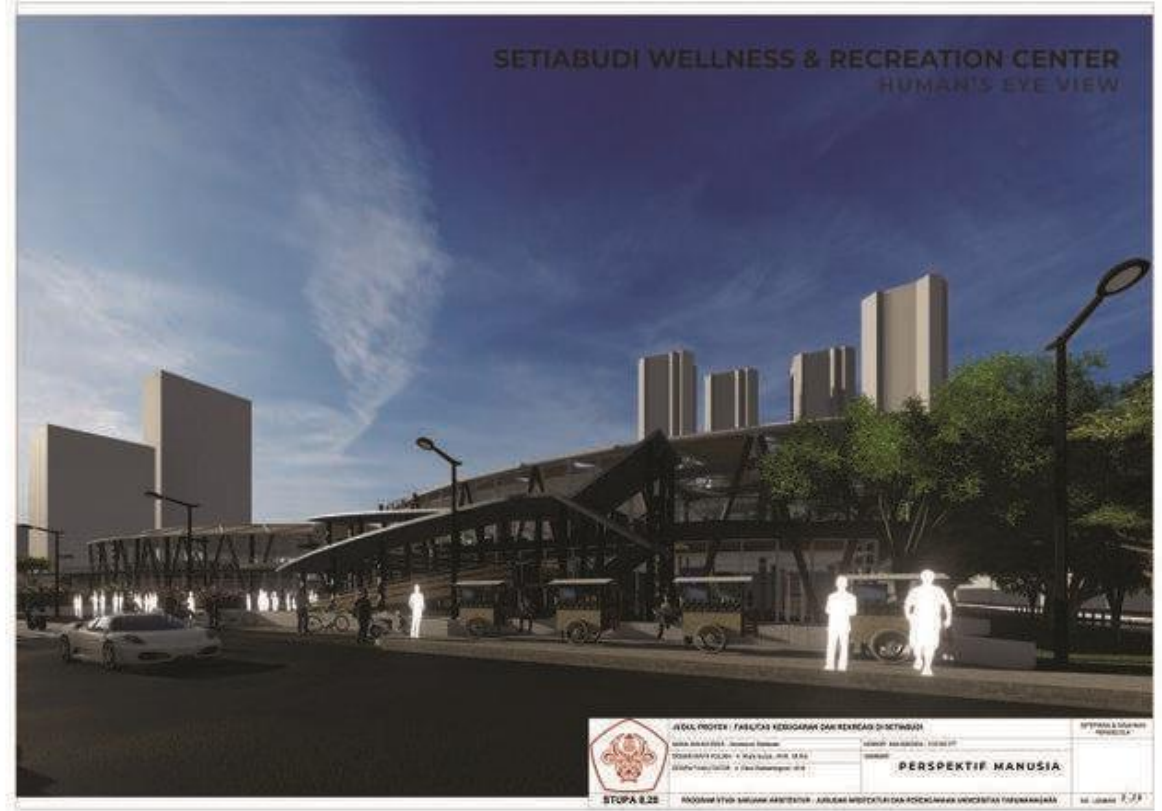

Gambar 5. Perspektif Manusia Terbaik Sumber: Penulis, 2019 

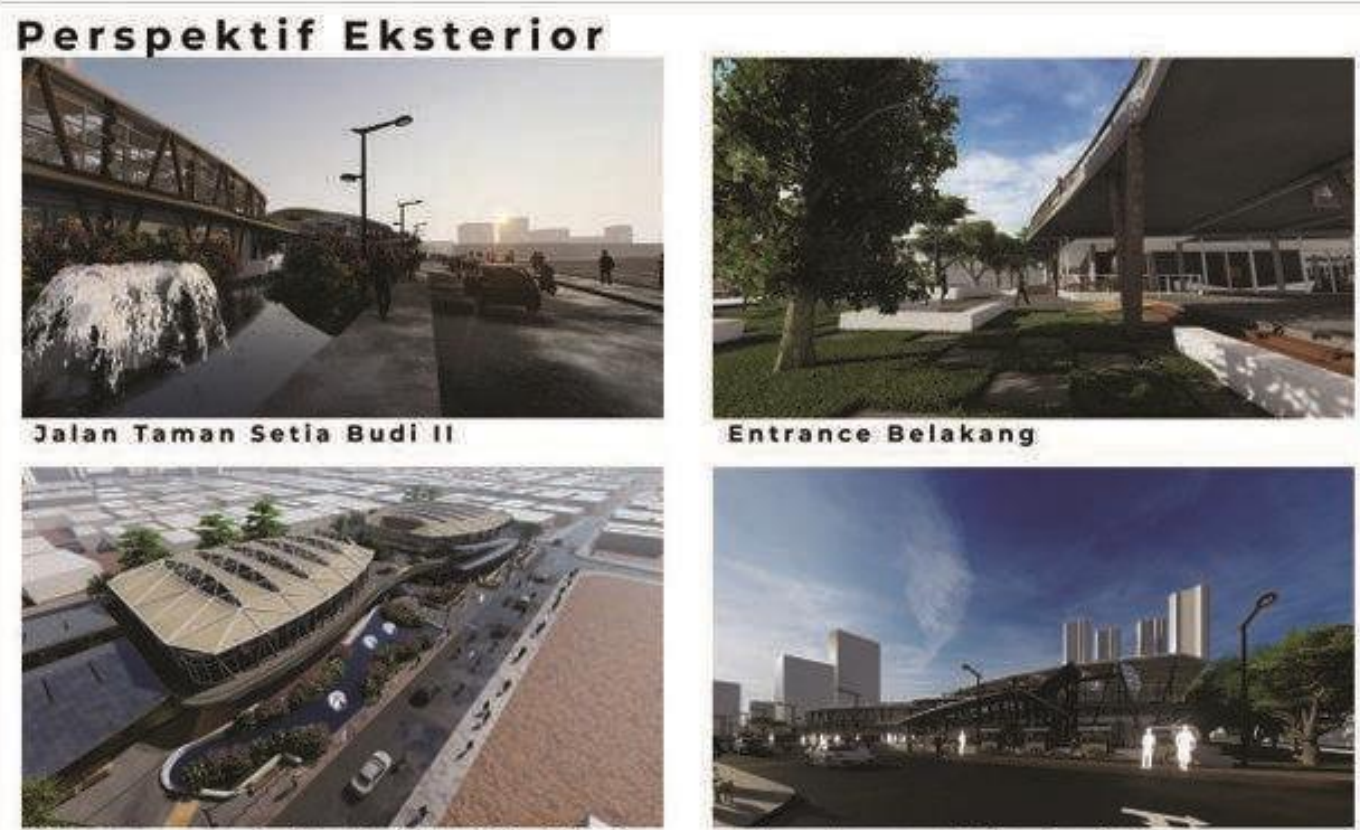

Jalan Taman Setia Budi II (Bird Eye)
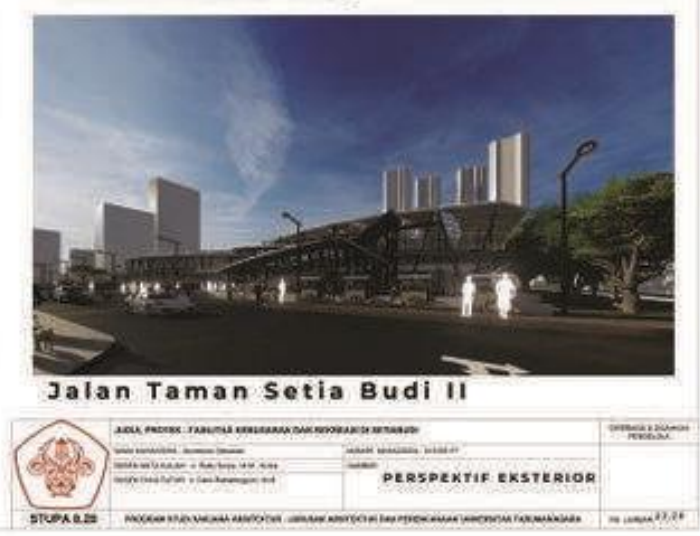

Gambar 6. Perspektif Eksterior

Sumber: Penulis, 2019

\section{Perspektif Interior}
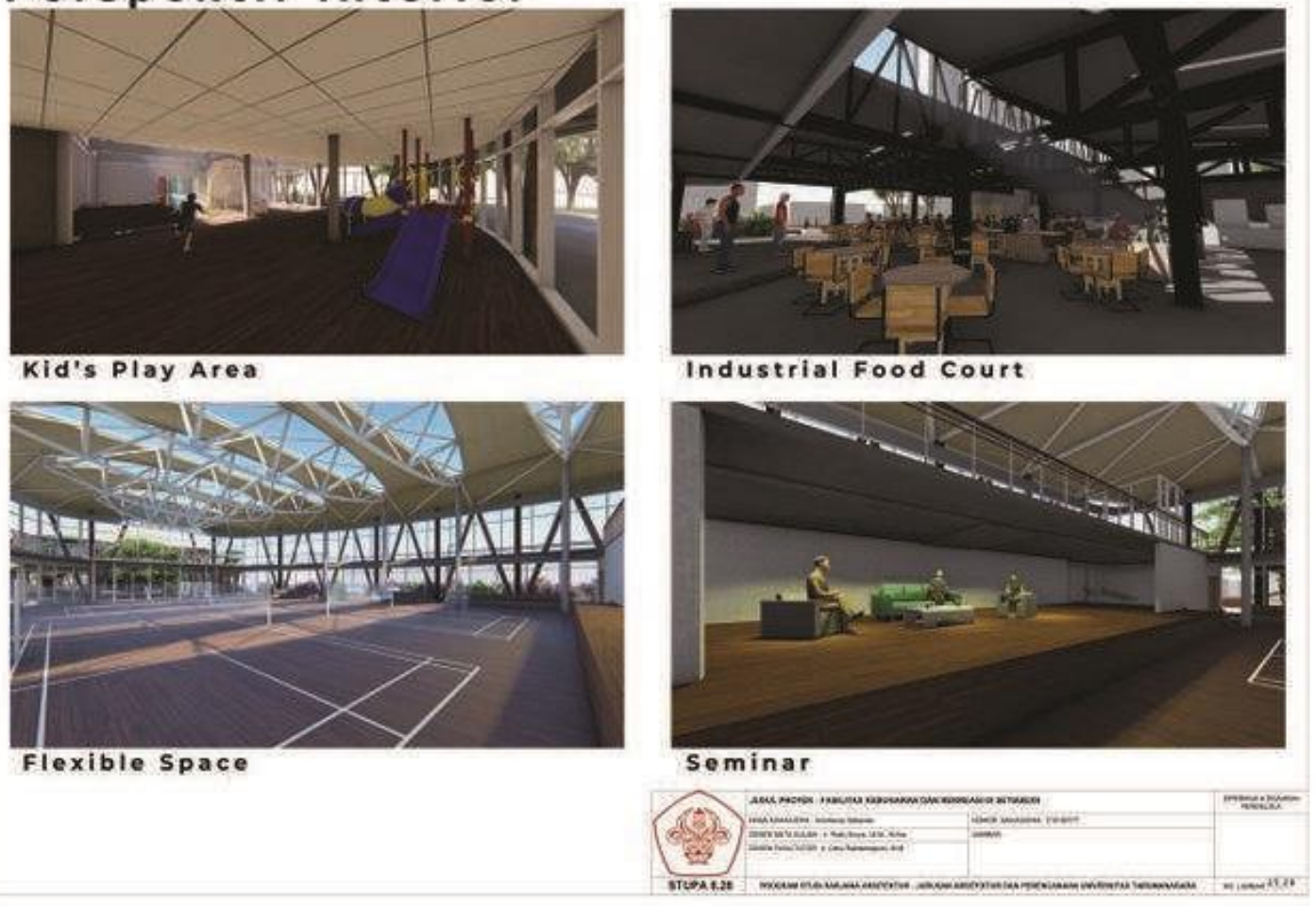

Gambar 7. Perspektif Interior

Sumber: Penulis, 2019 


\section{KESIMPULAN DAN SARAN}

\section{Kesimpulan}

Untuk memfasilitasi kegiatan sosial dan kebutuhan sekunder masyarakat Setiabudi, membutuhkan media yang wadah di mana seluruh masyarakat tersebut bisa bersenda gurau, melepas santai setelah sibuknya kerja kantor. Kurangnya ruang publik yang tersedia menyebabkan kebutuhan wadah sosial, ruang komunal yang inklusif melahirkan sarana/fasilitas yang bisa memenuhi kegiatan sosial dan kebutuhan sekunder masyarakat yaitu sarana kebugaran untuk memenuhi kebutuhan sekunder dan sarana rekreasi untuk memenuhi kegiatan masyarakat Setiabudi.

Konsep program yang mengutamakan fasilitas kebugaran sekaligus memadukan program rekreasi sebagai tempat melepas santai, melatih kebugaran serta konsep bangunan yang kontras dengan bangunan sekitar menjadi pusat berkumpul dan mudah diingat bagi masyarakat Setiabudi.

\section{Saran}

Penulis menyarankan bahwa melalui proyek Fasilitas Kebugaran dan Rekreasi di Setiabudi, Setiabudi bisa menjadi kawasan yang memfasilitasi seluruh masyarakatnya dengan aman dari gangguan lalu lalang kendaraan, serta menjadi tempat melepas santai setelah bekerja maupun sekolah juga sebagai ruang komunal masyarakat Setiabudi dan mencegah terjadinya degradasi sosial antara pendatang dan penduduknya.

\section{REFERENSI}

Badan Pusat Statistika. (2016). "Setiabudi dalam Angka 2016". Diakses tanggal 16 Juli 2019. https://jakselkota.bps.go.id/publication/2016/08/27/4e2b0a4137de5ba3a42654a2/setiabu di-dalam-angka-2016/

Florida, R. (2012). The Rise Of The Creative Class, Revisited. New York: INGRAM PUBLISHER SERVICES US

Jakarta MRT. (2019). "Kawasan Transit-Oriented Development (TOD)". Diakses 17 Juli 2019. https://www.jakartamrt.co.id/konektivitas/transit-oriented-development-tod/

Jiwangga. "Kebutuhan Ruang Ketiga”. Diakses 17 Juli 2019. http://jiwangga.com/MyPad/Entries/2005/9/2 Kebutuhan Ruang Ketiga.html/

Kobayashi, H. dan Leila A. (2001). The Concept of Openness in The Architectural Context. Hokkaido: Universitas Hokkaido

Larice, M. and Macdonald, E. (2007). The Urban Design Reader, second edition, Routledge [versi Elektronik]. New York: Architectural Press

McLaren, D. dan Julian A. (2015). Sharing Cities - A Case for Truly Smart and Sustainable Cities [versi Elektronik]. Cambridge: MIT Press

Oldenburg, R. (1999). The Great Good Place: Cafés, Coffee Shops, Bookstores, Bars, Hair Salons, and Other Hangouts at the Heart of a Community [versi Elektronik]. United States: Marlowe.

Penataan Ruang. "Rencana Tata Ruang Wilayah". Diakses 17 Juli 2019. https://jakartasatu.jakarta.go.id/portal/apps/webappviewer/index.html?id=ee9940006aae 4a268716c11abf64565b/

Segitiga Emas Jakarta. (2018). "Kawasan Segitiga Emas Jakarta". Diakses tanggal 16 Juli 2019. https://www.doyanjalan.com/kawasan-segitiga-emas-dki-jakarta/

Sustainable Development Goals. (2019). The Sustainable Development Goals, Diakses tanggal 16 Juli 2019. https://www.un.org/sustainabledevelopment/sustainable-developmentgoals/

Tschumi, B., (2005). Event- Cities 3: Concept vs. Context vs. Content [versi Elektronik]. MIT Press.Cambridge. Massachussetts. 